\title{
Concepções de professores de ciências biológicas sobre as aulas práticas
}

Ismailton Ferreira Martins ismailtonf@gmail.com orcid.org/ 0000-0002-1055-0992 Universidade do Estado de Minas Gerais (UEMG), Ibirité, Minas Gerais, Brasil

Shirley de Lima Ferreira Arantes

$\underline{\text { shirley.ferreira@uemg.br }}$ orcid.org/ 0000-0003-4998-1914

Universidade do Estado de Minas Gerais (UEMG), Ibirité, Minas Gerais, Brasil

\section{RESUMO}

Este artigo apresenta resultados de uma pesquisa que investigou as concepções de professores sobre aulas práticas no ensino de Ciências Biológicas, visando compreender: i) o papel que atribuem a essas atividades; ii) as dificuldades percebidas; e iii) estratégias utilizadas. Foi aplicado questionário semiestruturado online divulgado por meio da rede social Facebook em grupos de professores de Ciências. Foi realizada análise estatística de frequência simples dos dados quantitativos e análise de conteúdo das respostas discursivas. Participaram da pesquisa 23 professores, a maioria do sexo feminino (61\%), até 41 anos de idade (74\%), ensino superior completo (95\%), e pós-graduação (52\%). 95\% realizam aulas práticas no ensino de Ciências e avaliam que seu papel principal é complementar as aulas teóricas (52\%); motivar os alunos (18\%); e desenvolver as aulas (18\%). Metade das escolas públicas em que atuam/atuaram não dispõe de laboratório de Ciências, realizando práticas na sala de aula (45\%) e área externa (27\%), com dificuldades na consecução de insumos (82\%). Nas concepções dos professores, a realização de aulas práticas envolve fatores institucionais, a formação e qualificação docente, e características pessoais, como motivação e habilidades de gestão da sala de aula. Esses dados corroboram a literatura de referência, evidenciando, porém, tendência de maior consonância entre as crenças acerca da eficácia das atividades práticas para o ensino de Ciências, e as tarefas efetivamente executadas no cotidiano. Esses resultados sinalizam a urgência de políticas públicas de investimento na infraestrutura das escolas, e importância da difusão do ensino investigativo e experimentação na formação inicial e continuada de professores para a integração das concepções e das práticas no ensino de Ciências.

PALAVRAS-CHAVE: Ensino de Ciências. Atividades Práticas Investigativas. Formação de professores. 


\section{INTRODUÇÃO}

Existe um consenso entre os professores de Ciências acerca da relevância e das contribuições positivas das aulas práticas nos diferentes níveis da educação básica. Segundo Prado e Wesendonk (2019, p. 149) essa confiança persiste desde final de séc. XIX "período no qual as atividades práticas começaram a fazer parte dos currículos das disciplinas científicas na Inglaterra e nos Estados Unidos".

Porém, a literatura de referência evidencia que, essa posição discursiva, nem sempre é acompanhada pelo desenvolvimento efetivo de atividades práticas no espaço escolar. São observadas dificuldades dos professores de Ciências em relação à natureza do conteúdo, ao planejamento das atividades e à integração dos objetivos sociocognitivos das práticas (ANDRADE; MASSABNI, 2011; ARAÚJO; PEDROSA, 2014; BASSOLI, 2014; GEHLEN; MALDANER; DELIZOICOV, 2012; ROSA; ROSA; PECATTI, 2007).

Dentre os aspectos positivos das aulas práticas no ensino de Ciências, são destacados os estímulos ao interesse e à curiosidade dos alunos. Propiciando o diálogo, o compartilhamento e a interação social, convocam o pensamento reflexivo, e potencializam a aprendizagem da transmissão operada nas aulas teóricas. Através da experimentação, os estudantes compreendem conceitos científicos, ampliam sua capacidade de resolver problemas práticos do dia-a-dia, desenvolvem novas habilidades no laboratório e, também, vivenciam descobertas importantes em espaços como hortas e jardins, onde podem observar, examinar e conviver com outros seres vivos (ANDRADE; MASSABNI, 2011; BASSOLI, 2014; GEHLEN; MALDANER; DELIZOICOV, 2012; ROSA; ROSA; PECATTI, 2007).

Contudo, fatores que impactam negativamente o ensino de Ciências também devem ser considerados, sendo eles as desigualdades sociais estruturais no Brasil, a falta de políticas públicas e de recursos financeiros - que resultam na ausência ou na precarização de laboratórios - equipamentos, materiais e insumos nos estabelecimentos escolares, bem como a falta de preparo e de planejamento dos professores. Portanto, existem fatores condicionantes, particulares e/ou institucionais, que influenciam na decisão dos professores de utilizarem, ou não, a experimentação no ensino de Ciências (GEHLEN; MALDANER; DELIZOICOV, 2012; ROSA; ROSA; PECATTI, 2007).

Neste cenário, a figura do professor é fundamental. É importante compreender como esses atores significam e confrontam as condições objetivamente vivenciadas na educação básica, e que estratégias desenvolvem para o ensino de Ciências, a partir de uma perspectiva socialmente referenciada, propósito do presente trabalho.

Com base nestas considerações, o artigo apresenta e discute os resultados de uma pesquisa que investigou estas questões junto a professores de Ciências Biológicas da educação básica, compondo um quadro de suas principais demandas, desafios, e das estratégias didáticas utilizadas para a efetivação de aulas experimentais e outras atividades investigativas no cotidiano docente.

Participaram da pesquisa docentes oriundos de diferentes regiões do Brasil, alocados em escolas das redes pública e privada de ensino. Os resultados evidenciam que as aulas práticas são consideradas estratégia relevante de ensino; empregada pela quase totalidade da amostra. A seguir, são apresentados 
o percurso teórico empreendido na pesquisa, as estratégias metodológicas empregadas na construção dos dados empíricos, e os resultados da articulação dessas dimensões.

\section{A IMPORTÂNCIA DO ENSINO DE CIÊNCIAS BIOLÓGICAS}

Através do ensino de Ciências crianças e adolescentes entram em contato com temas importantes para o seu desenvolvimento psicossocial, como educação ambiental, saúde, cidadania, sustentabilidade, gênero e sexualidade, promovendo aprendizagens significativas (ARAÚJO; PEDROSA, 2014).

Segundo Carvalho (1997), as crianças trazem de casa uma série de concepções acerca do mundo em que vivem. No ensino fundamental, o ensino de Ciências é desenvolvido a partir desses conhecimentos espontâneos, desenvolvendo e ampliando suas percepções e pontos de vista, em uma perspectiva de provisoriedade da ciência.

Frequentemente, por meio do ensino de Ciências, questões associadas ao corpo humano, à saúde, ao gênero e à sexualidade são abordadas pela escola antes mesmo dos próprios pais conversarem sobre esses assuntos com seus filhos. Ainda, em uma perspectiva mais ampla do que a familiar, fortemente atravessada por questões de classe social e influenciada pela pertença religiosa. Dessen e Polonia (2007, p. 22) ao discutir a família e a escola como contextos de desenvolvimento humano nos recordam que, a família "constitui a unidade dinâmica das relações de cunho afetivo, social e cognitivo que estão imersas nas condições materiais, históricas e culturais de um dado grupo social".

Dessa forma, a escola cumpre funções fundamentais ao abordar essas temáticas, outorgando aos alunos a compreensão de fenômenos biológicos e subjetivos que os afetam, assim como o reconhecimento e a conscientização de possibilidades, dos riscos, dos cuidados com a saúde e com o corpo, e das estratégias de prevenção de doenças. O corpo, configurado como espaço privado, é também referido à dimensão pública e coletiva, quando as crianças e adolescentes são informados sobre aspectos sócio-políticos da cultura e da legislação, dentre outros. Além disto, contribui para a socialização de pensamentos, sentimentos e emoções que se relacionam à imagem que as crianças e adolescentes fazem de si, e à sua autoestima.

Para Cano, Ferriani e Gomes (2000), o hábito de reprimir dúvidas na escola também reflete as dificuldades que os pais vivenciam no dia-a-dia em dialogar sobre temas como o gênero e a sexualidade. Contudo, essa espécie de "terceirização" da educação sexual da criança, não ocorre apenas por mero desleixo ou descuido dos pais. Há que se considerar a necessidade de subsistência das famílias, que, frequentemente, obriga os mantenedores a realizarem longas e exaustivas jornadas de trabalho. Além disto, pais e mães podem, apenas, reproduzir a forma como foram educados por seus pais, tratando certos temas como tabus e reproduzindo preconceitos.

Através das aulas de Ciências, a criança, ou o adolescente, pode vir a perceber que o valor de todos os seres vivos é o mesmo, mudando sua forma antropocêntrica de compreensão do mundo. $\mathrm{O}$ aluno compreenderá que os seres humanos são apenas mais uma espécie e, não necessariamente, a melhor dentre 
as demais. A partir deste ponto, cria-se o respeito pelas diversas formas de vida, e a capacidade de reconhecimento de situações de desequilíbrio ambiental, favorecendo perspectivas de desenvolvimento sustentável.

\section{DIFICULDADES NO ENSINO DE CIÊNCIAS}

O ensino de Ciências é atravessado pelas desigualdades sociais estruturais da sociedade brasileira, reproduzidas nos estabelecimentos escolares. Em um país de dimensões continentais, existem diferenças profundas entre escolas das redes pública e privada, inclusive entre aquelas pertencentes à mesma rede, em função das características associadas à classe social, à raça, à localização geográfica, dentre outros fatores relacionados à clientela que atendem e aos agentes que nela atuam.

As escolas dispõem, e ofertam de modo diferenciado, de infraestrutura, de espaços como laboratórios, jardins e hortas, de equipamentos como microscópios e também insumos, como reagentes e lâminas, para a realização de aulas práticas. Também há dificuldades com relação à segurança e à adequada preparação do ambiente experimental. Contudo, sabemos que "aula prática não significa somente o espaço físico de um laboratório, pois o próprio ambiente pode servir como local" (BEREZUK; INADA, 2010, p. 214).

Além disto, os impactos das condições de trabalho docente nos estabelecimentos escolares também devem ser considerados. A precarização se desdobra sobre a atividade docente e, até mesmo, sobre a saúde mental dos professores, aumentando os índices de adoecimento, rotatividade e absenteísmo (MOREIRA; RODRIGUES, 2018).

Filho e Araújo (2017) destacam que diversos fatores incidem e ampliam o fenômeno da evasão escolar, multifacetado e pluridimensional. O uso de drogas, sucessivas reprovações, a prostituição, a falta de incentivo da família e também da escola. Uma escola não atrativa, métodos de ensino ultrapassados, a falta de estrutura adequada e a desmotivação dos professores, são fatores interrelacionados e também cruciais para que crianças e adolescentes percam o interesse pela escola, contribuindo para a defasagem idade-série e evasão escolar.

Dados da Pesquisa Nacional por Amostra de Domicílios de 2017 evidenciam que a taxa de escolarização de crianças e adolescentes de 6 a 14 anos é de 99,2\% em todo o território nacional. Isto sinaliza a universalização da primeira etapa da educação básica, favorecida por políticas públicas de acesso à renda como o programa Bolsa Família. Para adolescentes de 15 a 17 anos, a taxa de escolarização é de $87,2 \%$. Contudo, observa-se um aumento progressivo de estudantes atrasados e fora da escola no decurso da escolarização obrigatória em ambas às etapas da educação básica, acentuando-se no ensino médio.

Nesse sentido, é tarefa da escola e dos professores resguardar o direito ao estudo, expandir as perspectivas de inclusão social das crianças e adolescentes, cuja cidadania deve ser reconhecida e preservada. Estimular sua permanência na escola e fomentar o prolongamento das trajetórias de escolarização pode contribuir para a erradicação do funil que o ensino médio representa para a educação básica. 
Além destas questões do contexto mais amplo, as dificuldades no ensino de Ciências também se relacionam à natureza do conteúdo. Segundo Araújo e Pedrosa (2014) o estudo dos diferentes sistemas do corpo humano, por exemplo, integra conhecimentos adquiridos ao longo das séries escolares até os níveis mais complexos. Alguns conteúdos podem ser observados a olho nu, enquanto o ensino de genética, por exemplo, é favorecido pelo uso de microscópios. Temas abstratos, como a respiração e a fotossíntese, carecem de abordagens interdisciplinares, de conhecimentos prévios de química, e assim por diante.

Guimarães, Silva e Neto (2019) destacam que a linguagem matemática utilizada para expressar os fenômenos estudados na físico-química constitui uma das principais dificuldades da aprendizagem dos conceitos.

Silva, Sá e Batinga (2019) enfatizam que as atividades práticas contribuem justamente para que os conceitos interdisciplinares não sejam apresentados de forma fragmentada. Desse modo, as dificuldades dos professores devem ser consideradas:

\footnotetext{
Outros fatores constatados são a inadequação da explicação de alguns conceitos pelo professor; o curto tempo para exposição dos conceitos; a dificuldade do professor em responder às dúvidas dos alunos; a falta de discussão sobre determinados aspectos considerados importantes para ancorar o novo conhecimento; a grande quantidade de termos novos dos quais os alunos precisam se apropriar e a falta de atividades práticas ou experimentais para auxiliar na exposição do conteúdo, entre outros fatores (ARAÚJO; PEDROSA, 2014, p. 308).
}

De acordo com Carvalho (1997), a disciplina de Ciências no ensino fundamental pode ser considerada uma ponte entre o conhecimento empírico levado pelo aluno e os conceitos científicos ensinados pelo professor. Portanto deve ser realizado de forma consciente e responsável, de modo que não desvalorize ou ridicularize os conhecimentos prévios da criança. Se o ensino for sem sentido e exigir a pura memorização de conceitos abstratos fora do entendimento da criança, se for descompromissado com a sua realidade, a aversão ao campo científico será instalada.

Não obstante, assim como em outras áreas, o ensino de Ciências possui suas peculiaridades no que diz respeito à qualidade dos cursos de licenciatura, uma vez que os professores são desafiados "a usar conhecimento científico, tecnologias educacionais e estratégias didáticas inovadoras e criativas que, muitas vezes, não estiveram presentes na sua formação inicial" (SEIXAS; CALOBRÓ, 2017, p. 291). Esta afirmação nos leva a refletir sobre o papel das instituições de ensino superior. Se, de fato, estão contribuindo para que seus discentes tenham uma formação adequada, ou, estão apenas reproduzindo a lógica do sistema capitalista que visa à mercantilização da educação enquanto a qualidade do ensino é relegada ao segundo plano.

Seixas e Calobró (2017) aludem à formação docente como um quebracabeça nunca finalizado, cujos limites encontram-se permanentemente em aberto. Isto é, o professor de Ciências Naturais deve estar sempre se atualizando, não só devido a novos fatos científicos e descobertas, mas também em relação às exigências das novas gerações de alunos.

Crianças e adolescentes atualmente estão cada dia consumindo mais tecnologias e, consequentemente, mais informações, com isso, podemos concluir 
que, as instituições de ensino superior, os professores, e os próprios docentes em formação devem se adequar a essa nova realidade. Além disso, cabe ao professor reconhecer que, dentro de uma sala de aula, nem todos os alunos possuem os mesmos conhecimentos prévios, cada aluno possui diferentes experiências de vida, e, por isso, os seus conhecimentos são também diversificados.

Essa afirmação nos faz refletir sobre a responsabilidade do professor como mediador da aprendizagem, pois as diversas diferenças merecem atenções particulares, numa perspectiva de ação-reflexão: "[...] a heterogeneidade se manifesta das mais diferentes formas no contexto escolar, e é um desafio muito grande, para o professor, isoladamente, levar em conta todas as dimensões que a complexidade das situações impõe" (PIASSI, 2011, p. 798).

Ao falarmos da diversidade cultural existente em sala de aula, e que cabe ao professor tratá-las individualmente, esbarramos em um dos grandes problemas enfrentados pela educação pública, que é o excesso de alunos. A superlotação torna complexa a gestão de atividades práticas, culminando na reprodução conteudista.

Diante desse cenário o professor de Ciências deve interrogar seu papel social, sendo desafiado a romper com a reprodução de estereótipos, preconceitos e relações de subordinação, de modo que tais mudanças repercutam, a médio e longo prazo, sobre a conjuntura mais ampla.

Não obstante, perante as adversidades, os professores de Ciências buscam alternativas para que consigam lecionar de forma mais dinâmica e agradável, favorecendo a absorção dos conteúdos de maneira mais espontânea pelos alunos, tema que será desenvolvido a seguir.

\section{ENSINO DE CIÊNCIAS E AULAS PRÁTICAS}

Atividades práticas investigativas podem ser definidas como "aquelas tarefas educativas que requerem do estudante a experiência direta com o material presente fisicamente, com o fenômeno e/ou com dados brutos obtidos do mundo natural ou social" (ANDRADE; MASSABNI, 2011, p. 840), quer o aluno desenvolva manualmente a tarefa ou observe a demonstração do professor. Além disso, "é desejável que haja a maior interatividade possível destes com os objetos e fenômenos", interatividade física, emocional, e, sobretudo, intelectual (BASSOLI, 2014, p.581), envolvendo os alunos na discussão de ideias, elaboração de hipóteses e experimentação.

Essa perspectiva interacionista no ensino de Ciências vai ao encontro das contribuições de Lev S. Vygotsky para o campo da educação. De acordo com Vygotsky (1989), a escola é uma instituição fundamental para que o aluno seja capaz de construir pontes, e de realizar travessias, entre os conhecimentos empíricos, apreendidos espontaneamente por meio das vivências cotidianas no ambiente da socialização primária familiar, e os conhecimentos científicos, historicamente formulados pela cultura, a qual está sendo introduzido no universo escolar.

Segundo Vygotsky (1984) a elaboração conceitual dos conceitos científicos torna-se mais complexa à medida que se desenvolvem as funções psicológicas superiores, como a memória, a atenção voluntária, e a linguagem, internalizadas 
nas relações sociais. O processo de apropriação intencional e voluntária do conhecimento científico permitirá ao sujeito explicar, de forma consciente, a realidade da vida cotidiana, e solucionar situações problemáticas em seu dia-adia.

Cabe ao professor organizar as situações de ensino para que o aluno perceba-se como protagonista do processo de aprendizagem, superando a memorização e integrando os novos conhecimentos à sua cultura. Quanto maior o envolvimento do aluno com as atividades, "melhor o seu aprendizado, pois ele aprende a tirar suas próprias conclusões, favorecendo pensamentos e atitudes entre ciência, tecnologia e sociedade" (BARTZIK; ZANDER, 2016, p. 31).

Vygotsky $(1984 ; 1991)$ considera que a escola é um importante mediador entre a criança e o conhecimento científico. Ela cumpre funções importantes no processo de desenvolvimento e aprendizagem, pois por meio da ação docente estimula a região de aprendizagem que o autor denomina zona de desenvolvimento proximal do aluno, ou seja, aquele intervalo entre aquilo que o aluno já sabe, o seu nível de desenvolvimento real, e aquele conhecimento potencial, o que será capaz de aprender sozinho, ou, com a ajuda de um par mais avançado.

Nesse sentido, a diversificação das estratégias didáticas utilizadas no cotidiano escolar favorece o engajamento intelectual dos alunos, a aprendizagem e a abstração dos conceitos, e sua generalização para outras situações. O professor pode recorrer a explicações verbais, aulas expositivas, demonstração, assistência, fornecimento de pistas, atividades em laboratórios, em pequenos grupos, pode recorrer ao auxílio de tecnologias da comunicação e informação, dentre outras possibilidades que estimulam a interação do estudante com o objeto do conhecimento:

Quando o professor estimula o diálogo, a cooperação entre pares, a troca de informações, o confronto de ideias, a divisão de tarefas e a ajuda mútua, está atuando de forma a propiciar a construção de conhecimentos numa ação partilhada, pois segundo Vygotsky, as relações entre sujeito e objeto do conhecimento são estabelecidas através dos outros (JOENK, 2002, p. 9).

Cabe lembrar que os Parâmetros Curriculares Nacionais para as Ciências Naturais (PCN) indicam, como objetivos do ensino fundamental, que os alunos sejam capazes de: "posicionar-se de maneira crítica, responsável e construtiva nas diferentes situações sociais, utilizando o diálogo como forma de mediar conflitos e de tomar decisões coletivas" (BRASIL, 1997, p. 7), posicionando-se contra qualquer discriminação, contribuindo ativamente para a melhoria do meio ambiente, resguardando o respeito a si e ao outro, agindo com responsabilidade em relação à própria saúde e à saúde coletiva, sendo perseverante na busca de conhecimento, e exercitando a capacidade de utilizar o pensamento lógico, a criatividade e os princípios científicos e tecnológicos para questionar a realidade e solucionar problemas.

Desse modo, o planejamento e a integração dos diferentes momentos pedagógicos contribuem para que haja maior interesse por parte dos alunos nos conteúdos em tela. São mobilizados seus conhecimentos prévios, desenvolvida sua capacidade de problematização, e construídas novas sínteses que potencializam o desenvolvimento e a aprendizagem (GEHLEN; MALDANER; DELIZOICOV, 2012). 
Assim, não basta que o professor proponha atividades práticas à classe; é preciso fazê-lo de modo coerente, dentro de um planejamento mais amplo. 0 planejamento deve envolver objetivos claros e específicos, etapas definidas e bem construídas, para que os alunos possam atribuir significados às atividades (ANDRADE; MASSABNI, 2011; BASSOLI, 2014; GEHLEN; MALDANER; DELIZOICOV, 2012; ROSA; ROSA; PECATTI, 2007; PRADO; WESENDONK, 2019).

Como se busca evidenciar no presente artigo, as aulas práticas no ensino de ciências favorecem estas premissas: a interação social; as trocas dialógicas; a cooperação; e a criatividade - ao deslocar a ênfase do conteúdo a ser transmitido e imediatamente assimilado, em direção ao processo de construção e compreensão dos conteúdos em uma perspectiva cooperativa, disciplinar, e interdisciplinar. Em ambientes formais e não formais de ensino envolvem ainda uma dimensão lúdica:

[...] ao realizar atividades 'lúdicas', com uma visão construtivista da Ciência, estamos dando oportunidade às crianças de exercer suas habilidades e desenvolver sua capacidade crítica e reflexiva, pois o desenvolvimento das estruturas cognitivas é a base para que a criança possa construir os conceitos e entender os princípios de todas as áreas do conhecimento (GADÉA; DORN, 2011, p. 113).

Por fim, recordamos que, de modo geral, as aulas de Ciências são cercadas por expectativas positivas dos alunos (PIRES, et al, 2007). Prado e Wesendonk (2019) consideram que a experimentação é um recurso didático com potencial motivador. Portanto, é importante compreender a realidade encontrada pelos professores na educação básica, e as estratégias que desenvolvem para o ensino. A seguir, apresentaremos os passos empregados nesta pesquisa para investigar estas questões junto aos professores.

\section{METODOLOGIA}

Esta pesquisa foi apresentada ao Comitê de Ética em Pesquisa sob o CAAE: 01435118.6.0000.5525 e aprovada quanto aos aspectos éticos pelo parecer 3.143.132.

Trata-se de uma pesquisa de abordagem quantitativa e qualitativa, exploratória quanto aos seus objetivos, pois "busca apenas levantar informações sobre um determinado objeto, delimitando assim um campo de trabalho" (SEVERINO, 2007, p. 123). A pesquisa foi levada a cabo por meio da técnica da "observação direta extensiva" a qual, é definida por Marconi e Lakatos (2004, p. 201): "A observação direta extensiva realiza-se através do questionário, do formulário, de medidas de opinião e atitudes e de técnicas mercadológicas".

De acordo com Severino (2007, p. 125), o questionário consiste em um conjunto de questões "sistematicamente articuladas, que se destinam a levantar informações escritas por parte dos sujeitos pesquisados, com vistas a conhecer as opiniões dos mesmos sobre os assuntos em estudo". O questionário apresenta uma série de vantagens, como a economia de recursos e tempo, o alcance simultâneo de muitos indivíduos, a abrangência geográfica ampliada, e o fato de minorar eventuais distorções pela interpretação do pesquisador. Mas, também, apresenta desvantagens como a pequena percentagem de retorno, a devolução 
tardia, o desconhecimento das situações de preenchimento e assim por diante (MARCONI; LAKATOS, 2004).

Para o alcance dos objetivos dessa pesquisa, foi construído um questionário semiestruturado. A primeira seção do questionário visou breve caracterização sociodemográfica dos participantes (idade; sexo), perfil formativo e experiência docente (ano de conclusão da graduação; titulação; atuação na rede pública e/ou particular; etc.). A segunda seção investigou os desafios e as demandas dos professores. A quarta e última seção tratou das estratégias metodológicas efetivamente empregadas em seu cotidiano docente.

Considerada a dispersão do público-alvo, a saber, professores de Ciências Biológicas da rede pública e da rede privada de ensino na educação básica, foi construído um questionário contendo questões abertas e fechadas, por meio da plataforma Google Forms, como formulário eletrônico online, com respostas em múltipla escolha, resposta curta e resposta em parágrafo. A utilização de formulários eletrônicos online na pesquisa científica delineia uma tendência importante, mediante a conectividade de uma parcela expressiva da população:

\footnotetext{
Esse crescente uso da internet em todas as faixas etárias tem instigado os investigadores a desenvolverem questionários virtuais como um método alternativo para a obtenção de respostas em pesquisas científicas. 0 ambiente virtual proporciona, de forma flexível e dinâmica, a formação de redes de pessoas que compartilham ideias e experiências em comum (FALEIROS; KÄPLER; PONTES; SILVA; GOES; CUCICK, 2016, p. 2).
}

As pesquisas desenvolvidas através de formulários digitais apresentam maior praticidade para o entrevistado, que pode escolher o momento conveniente para a participação, não precisa se deslocar até o local da entrevista, entre outros aspectos da autoaplicação digital. Também oferecem vantagens ao pesquisador, tais como a organização automática dos dados e o armazenamento das respostas: "a possibilidade de criação de formulários eletrônicos é um facilitador no que diz respeito à distribuição da pesquisa aos entrevistados e, posteriormente, à organização e análise dos dados" (OLIIVEIRA; JACINSKI, 2017, p. 9).

A divulgação do questionário foi realizada por meio da postagem de link na rede social Facebook, com convite de participação voluntária na pesquisa, dirigido ao público-alvo, professores de Ciências Biológicas das redes pública e privada da educação básica. A primeira janela do formulário apresentava o Termo de Consentimento Livre e Esclarecido (TCLE) virtual, que deveria ser aceito pelo participante para que tivesse acesso às seções seguintes.

O link para o formulário esteve ativo por um período de 25 dias, e foi respondido por 23 professores de Ciências Biológicas $(N=23)$, que atuam ou atuaram em 41 escolas de educação básica, localizadas em 26 cidades, distribuídas em 07 estados brasileiros. Com relação à confiabilidade, todos os questionários foram completamente respondidos e incluídos na análise.

Os nomes dos entrevistados foram substituídos por números, sendo os questionários numerados de 1 a 23. Os dados e informações obtidos foram analisados e interpretados em forma de gráficos e textos à luz da literatura de referência. As respostas às questões abertas foram transcritas e submetidas à análise de conteúdo (BARDIN, 1977). A seguir, esses resultados são apresentados. 


\section{RESULTADOS E DISCUSSÃO}

Participaram da pesquisa 14 respondentes de questionário autodeclarados do sexo feminino e 09 respondentes do sexo masculino, respectivamente $60,86 \%$ e 39,14\% da amostra (Tabela 1). Esta proporção corrobora com os dados de Carvalho (2018) que pesquisou o perfil do professor da educação básica no Brasil, evidenciando que as mulheres são $68,9 \%$ do total de professores dos anos finais da educação básica, e representam $59,6 \%$ dos professores do ensino médio. Nesse intervalo da educação básica em que se concentram as disciplinas de ciências evidencia-se uma distribuição por sexo proporcional a amostra da presente pesquisa.

Tabela 1 - Professores da educação básica, por sexo

\begin{tabular}{ccc} 
Sexo & $\mathbf{N}^{\circ}$ & Percentual \\
Feminino & 14 & 60,86 \\
\hline Masculino & 09 & 39,14 \\
\hline Outro & 0 & 0 \\
\hline Total & 23 & 100.00 \\
\hline
\end{tabular}

Fonte: Autoria própria (2019).

Com relação à idade, nenhum professor que participou da pesquisa tem menos de 21 anos, e os profissionais com mais de 42 anos representam pouco mais de $26,1 \%$ dos respondentes (Tabela 2). No estudo de Carvalho (2018), a idade média dos professores da educação básica é de 42 anos, sendo que a autora aponta uma correlação positiva entre a idade e a escolarização, com concentração dos professores mais jovens e menos escolarizados nas etapas iniciais da educação básica. Além disso, a menor participação de docentes mais velhos na pesquisa online pode estar associado à mídia utilizada, uma rede social recorrente entre os mais jovens. No entanto, de acordo com Faleiros, et al (2016, p. 2), "embora os grupos etários mais jovens continuem a ter a maior taxa de uso da internet, a adesão de pessoas de faixas etárias mais avançadas a esta ferramenta tem aumentando nos últimos anos".

Tabela 2 - Professores da educação básica, por idade

\begin{tabular}{ccc} 
Idade & $\mathbf{N}^{\circ}$ & Percentual \\
Até 21 anos & 0 & 0 \\
\hline 22 a 26 anos & 05 & 21,73 \\
\hline 27 a 33 anos & 07 & 30,44 \\
\hline 34 a 41 anos & 05 & 21,73 \\
\hline 42 a 49 anos & 03 & 13,05 \\
\hline Mais de 50 anos & 03 & 13,05 \\
\hline Total & 23 & 100.00 \\
\hline
\end{tabular}

Fonte: Autoria própria (2019).

Com relação à formação, a Figura 1 evidencia que 95,66\% dos professores cursaram ensino superior completo. Este percentual é superior ao encontrado na pesquisa de Carvalho (2018), que verificou que $78,4 \%$ dos professores da educação básica no Brasil cursaram ensino superior, e se aproxima dos índices 
com escolaridade mais alta atende ao redesenho da carreira que associa remuneração com melhor formação, é uma tendência nacional alinhada às metas estabelecidas a partir da LDB, predominante nas regiões urbanas.

Em relação à pós-graduação, $30,43 \%$ dos professores cursaram especialização lato sensu e $21,74 \%$ stricto sensu (8,69\% mestres e $13,05 \%$ doutores). Estas médias são mais altas que as nacionais em que $95,4 \%$ cursaram especialização, 4,1\% mestrado e, apenas $0,5 \%$, doutorado.

Os dados da Figura 1 podem ser correlacionados à Tabela 2, no sentido de evidenciar as dificuldades dos professores com menos de 21 anos ou ainda em processo de formação de ingressar nesse mercado de trabalho. Portanto, a função docente na educação básica não se caracteriza como porta de entrada para o mercado de trabalho para os mais jovens.

Figura 1 - Formação acadêmica dos professores, considerada a titulação mais alta

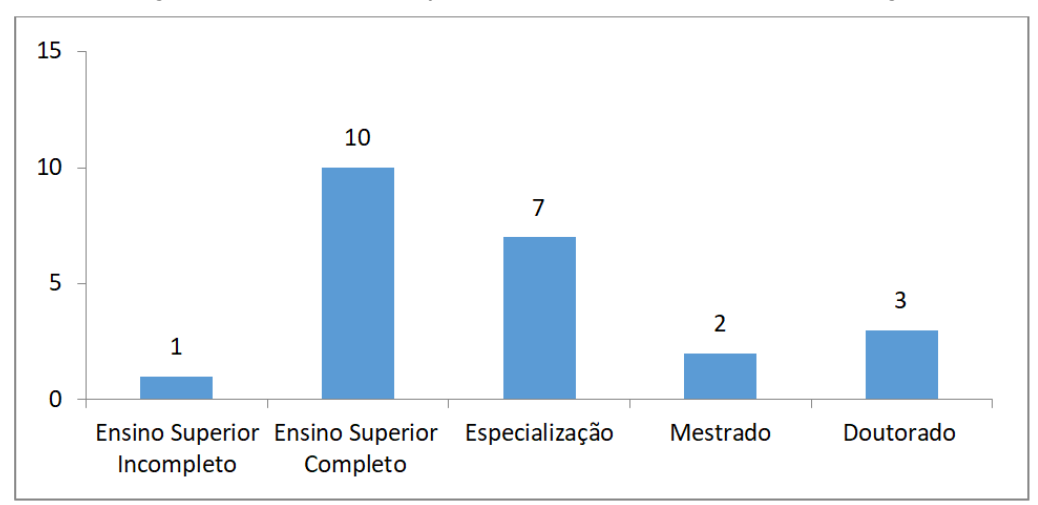

Fonte: Autoria própria (2019).

Com relação à experiência docente, $60 \%$ dos respondentes atuam profissionalmente há menos de 5 anos. Portanto, a amostra configura um grupo de professores recém-formados, cujos conhecimentos são potencialmente atualizados, que podem encontrar-se menos "desgastados" pela precariedade das condições de trabalho e, possivelmente, motivados para a atividade.

Figura 2 - Experiência docente, por anos de atuação

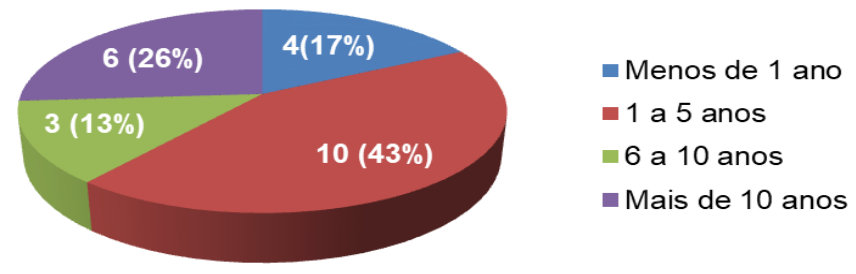

Fonte: Autoria própria (2019).

Conforme dito anteriormente, os professores que participaram da pesquisa atuam ou atuaram em mais de quarenta escolas da educação básica em diferentes cidades e estados do País. A Figura 3 apresenta a distribuição destes estabelecimentos nas redes pública e particular e a presença ou ausência de 
$83,4 \%$ das escolas da rede federal possuem laboratórios de ciências; $37,5 \%$ da rede estadual; $28,8 \%$ da rede municipal e $57,2 \%$ da rede privada.

No presente estudo, os estabelecimentos foram agregados, na rede pública $66,6 \%$ possuem laboratório para o ensino de Ciências e, na rede particular, este percentual alcança $80 \%$. Portanto, a ausência de laboratórios de ciências não é uma exclusividade das escolas públicas, ainda que em menor proporção, instituições privadas também enfrentam problemas desta natureza.

Figura 3 - Escolas estruturadas com laboratórios de Ciências, por rede de ensino

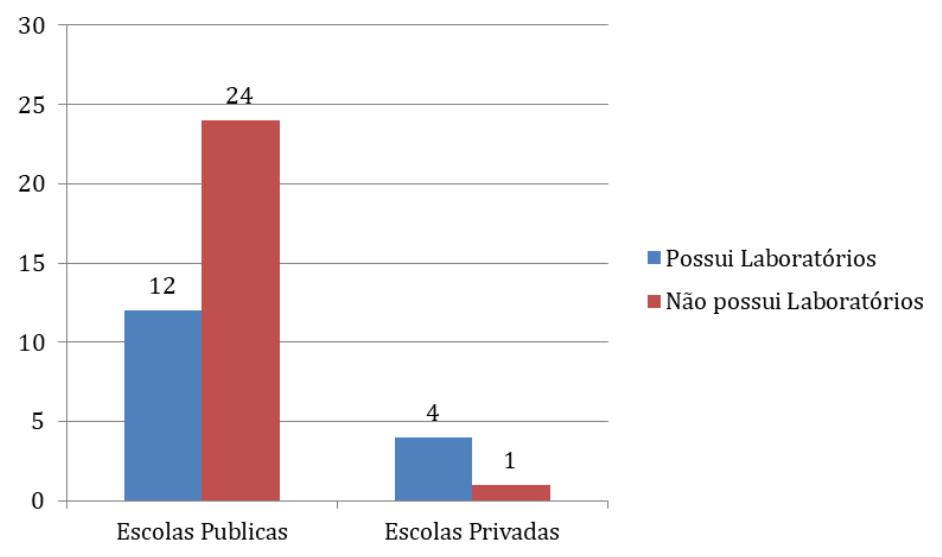

Fonte: Autoria própria (2019).

Os dados da pesquisa mostram, dentre outros aspectos, que a ausência de laboratórios não tem impedido a realização de aulas práticas pelos professores de ensino de Ciências.

Apenas 1, dos 23 professores que participaram da pesquisa, declarou não realizar aulas práticas para o ensino de Ciências. Em relação ao local de realização das aulas práticas, a Figura 4 mostra que a maioria dos professores, $45 \%$ da amostra, afirmam realizar dentro da própria sala de aula, enquanto o restante dos entrevistados indicou áreas externas (27\%) e laboratório (23\%). Apenas 1 professor afirmou utilizar as três áreas em igual proporção.

Figura 4 - Locais onde os professores realizam aulas práticas

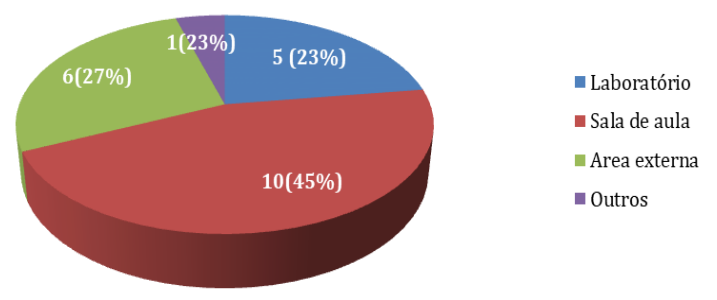

Fonte: Autoria própria (2019).

A Tabela 3 mostra que os professores que realizam aulas práticas $(\mathrm{N}=22)$, enfrentam dificuldades para conseguir materiais nos estabelecimentos escolares. Na maioria das vezes, tais dificuldades são contornadas por meio da utilização de materiais de baixo custo e de fácil acesso no dia a dia, minorando também eventuais riscos para os estudantes. Além de contarem com a ajuda de outros 
professores, sendo alguns de outras disciplinas, e em alguns casos até de alunos para a consecução de materiais.

Tabela 3 - Percepção de dificuldades para a obtenção de insumos para aulas práticas

\begin{tabular}{ccc}
\hline $\begin{array}{c}\text { Dificuldades para obter } \\
\text { insumos }\end{array}$ & $\mathbf{N}^{\circ}$ & Percentual \\
\hline Sim & 18 & 82 \\
\hline Não & 04 & 18 \\
\hline Total & 22 & 100.00 \\
\hline
\end{tabular}

Fonte: Autoria própria (2019).

Questionamos os professores sobre a aceitação das aulas práticas pelos alunos. Entre aqueles que realizam aulas práticas $(N=22)$ a maioria considera que são bem aceitas pelos alunos (86,36\%). Com relação às respostas negativas, os professores atribuem a não realização das aulas práticas ao desinteresse dos alunos. Na percepção dos docentes, em algumas aulas, os estudantes apresentam-se dispersos e não participam com empolgação das atividades. Porém, os respondentes não informaram fatores explicativos para esse fenômeno, se a desmotivação dos alunos estaria associada ao conteúdo em tela, ou outro fator.

A Figura 6 evidencia que o principal objetivo dos professores ao utilizarem aulas práticas no ensino de Ciências é complementar o conteúdo teórico ministrado. Na amostra da pesquisa, as aulas práticas não compõem etapas introdutórias do ensino.

Figura 6 - Percepção dos professores sobre os objetivos das aulas práticas

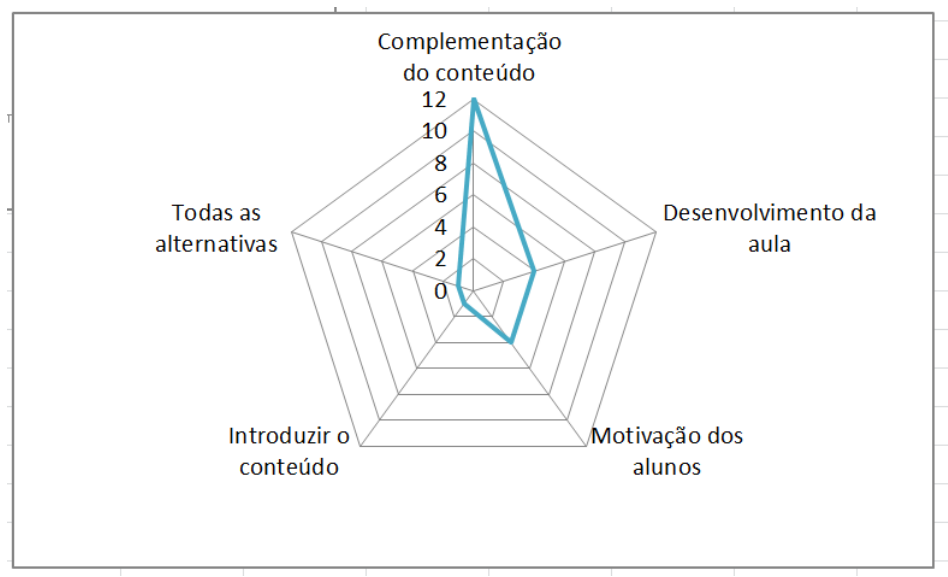

Fonte: Autoria própria (2019).

Solicitamos aos docentes que informassem as razões pelas quais alguns professores não realizam aulas práticas. Os fatores elencados dizem respeito à escola de atuação, à formação recebida e a características pessoais: "Falta de tempo para planejar as aulas, estruturas e materiais" (Q4); "Falta de apoio pedagógico por parte da gestão escolar" (Q11); "Preguiça ou despreparo dos professores" (Q15).

Os docentes destacaram a importância das aulas experimentais enfatizando investigação dá um sentido mais dinâmico às aulas: "Muito importante, pois 
ajuda a concretizar o que foi dito em sala" (Q1); "Desperta na criança o interesse científico" (Q8); "Aprender a teoria na prática torna a aula mais motivadora" (Q19).

Conforme dito anteriormente, os professores sinalizaram dificuldades na obtenção de insumos para as aulas práticas (Tabela 3). Apenas 16, das 41 escolas de atuação dos docentes, possuem laboratórios (Figura 3). Mesmo sob essas condições adversas, quando questionados sobre as estratégias didáticas adotadas, em geral, as respostas nos levaram a compreender que os professores procuram superar tais problemas através de metodologias didáticas alternativas. Ademais, a cooperação por parte de professores de outras disciplinas e até de alunos se destacaram entre as resposta: "Utilizo de materiais de fácil acesso no dia-a-dia" (Q7); "Conto com a doação de professores de outras disciplinas, dependendo da prática peço para os alunos trazer de casa" (Q9); "Às vezes utilizo jogos didáticos, os alunos adoram" (Q21).

\section{CONSIDERAÇÕES FINAIS}

O percurso teórico e empírico empreendido na presente pesquisa corrobora a perspectiva de que o desenvolvimento de aulas práticas e atividades experimentais constitui tarefa de suma importância no ensino de Ciências, caracterizando um eixo estruturante do planejamento docente.

O professor deve compreender que as contribuições das atividades práticas envolvem a transposição didática de definições e fórmulas abstratas para experiências mais concretas e objetivas no processo ensino-aprendizagem de Ciências. E, de modo articulado, promovem a sociabilidade e o desenvolvimento integral dos discentes.

No entanto, no cotidiano dos estabelecimentos escolares, os professores enfrentam dificuldades de várias ordens no desenvolvimento das aulas práticas. Essas dificuldades envolvem aspectos econômicos, socioculturais, da infraestrutura das escolas, do interesse dos estudantes, mas, também, da sua formação nos cursos de licenciatura, experiência e preparo emocional para a gestão da sala de aula e para o debate aberto de conteúdos multidisciplinares e interdisciplinares.

Contudo, com e contra essas dificuldades, a maior parte dos jovens professores que participaram da pesquisa persiste na construção das possibilidades de um ensino experimental e investigativo, que fomente a curiosidade e a criatividade, rompendo com práticas conteudistas, calcadas na memorização.

Evidenciam consonância entre suas crenças acerca da eficácia das atividades práticas para o ensino de Ciências, e as tarefas efetivamente executadas no cotidiano docente na educação básica.

Nesse ato educativo cumprem importantes funções sociais da docência no ensino de Ciências, rompendo com a reprodução de estereótipos que elevam os conhecimentos científicos a um patamar intangível para boa parte dos alunos, quiçá daqueles mais pobres. 
Por fim, ao pressupor que adequações de suas estratégias metodológicas são necessárias e importantes, professores de Ciências Biológicas concebem, sobretudo, que seus alunos são capazes de aprender Ciências. 


\title{
Biological sciences teachers' conceptions about practical classes
}

\begin{abstract}
This article presents the results of a research that investigated teachers' conceptions about practical classes for the teaching of Biological Sciences, aiming at understanding: i) the role they attribute to these activities; ii) the difficulties perceived by them; and iii) strategies used. An online semi-structured survey was disseminated and applied to groups of science teachers through the Facebook social network. Statistical analysis of the simple frequency of quantitative data and content analysis of discursive responses were carried out. 23 teachers participated in the survey, most of them female (61\%), up to 41 years of age (74\%), complete higher education (95\%), and graduate studies (52\%). 95\% hold practical classes in science teaching and evaluate that their main role is to complement theoretical classes (52\%); motivate students (18\%); and develop classes (18\%). Half of the public schools in which they work/worked lack a science laboratory, performing practices in the classroom (45\%) and external area (27\%), with difficulties in obtaining inputs (82\%). In the conceptions of the teachers, the implementation of practical classes involves institutional factors, the education and qualification of the teacher, and personal features, such as motivation and skills for classroom management. These data corroborate the literature in reference, emphasizing, however, a tendency of greater consonance between the beliefs about the effectiveness of practical activities for the teaching of Sciences and the tasks effectively performed in daily life. These results point to the urgency for public policies to invest in schools' infrastructure, and the importance of disseminating investigative teaching and experimentation during the initial and continuing teachers' education so that concepts and practices in science teaching are integrated.
\end{abstract}

KEYWORDS: Teaching of Sciences. Investigative Practical Activities. Teachers' Education. 


\section{AGRADECIMENTOS}

Agradecemos à Pró-Reitoria de Pesquisa e Pós-Graduação da Universidade do Estado de Minas Gerais a concessão de bolsa do Programa Institucional de Apoio à Pesquisa (PAPq/UEMG) para a realização desse trabalho.

\section{REFERÊNCIAS}

ANDRADE, M. L. F.; MASSABNI, V. G. O desenvolvimento de atividades práticas na escola: um desafio para os professores de ciências. Ciência \& Educação, Bauru, v. 17, n. 4, p. 835-854, 2011. Disponível em: https://www.scielo.br/scielo.php?pid=S151673132011000400005\&script=sci_abstract\&tlng=pt. Acesso em: 03 ago. 2019.

ARAUJO, M. F. F.; PEDROSA, M. A. Ensinar ciências na perspectiva da sustentabilidade: barreiras e dificuldades reveladas por professores de biologia em formação. Educação em Revista, Curitiba, n. 52, p. 305-318, jun. 2014. Disponível em: https://www.scielo.br/scielo.php?pid=S010440602014000200018\&script=sci_abstract\&tlng=pt. Acesso em: 25 jun. 2019.

BARDIN, L. Análise de conteúdo, São Paulo: Edições 70, 2011.

BARTZIK, F.; ZANDER, L. D. A Importância das aulas práticas de ciências no Ensino Fundamental. @rquivo Brasileiro de Educação, Belo Horizonte, v. 4, n. 8, p. 3138, 2016. Disponível em:

http://periodicos.pucminas.br/index.php/arquivobrasileiroeducacao/article/view /P.2318-7344.2016v4n8p31. Acesso em: 10 set. 2019.

BEREZUK, P. A.; INADA, P. Avaliação dos laboratórios de ciências e biologia das escolas públicas e particulares de Maringá, Estado do Paraná. Acta Scientiarum. Human and Social Sciences, Maringá, v. 32, n. 2, p. 207-215, 2010. Disponível em:

http://www.periodicos.uem.br/ojs/index.php/ActaSciHumanSocSci/article/view/ 6895. Acesso em: 05 abr. 2020.

BONDIA, J.L. Notas sobre a experiência e o saber da experiência. Revista Brasileira de Educação, Rio de Janeiro, n. 19, p. 20-28, 2002. Disponível em: https://doi.org/10.1590/S1413-24782002000100003. Acesso em: 15 jun.2018.

BRASIL, IBGE. Pesquisa Nacional por amostra de domicílios contínua, 2016-2017 - Educação. IBGE, 2017.

BRASIL, INEP. Notas estatísticas: censo escolar 2018. Brasília, jan. 2019. Disponível em: http://download.inep.gov.br/educacao_basica/censo_escolar/notas_estatisticas/ 2018/notas_estatisticas_censo_escolar_2018.pdf. Acesso em: 10 mar. 2020.

BRASIL. Secretaria de Educação Fundamental. Parâmetros curriculares nacionais: ciências naturais/Secretaria de Educação Fundamental. - Brasília: MEC/SEF, 1997. 
CANO, M. A. T.; FERRIANI, M. G. C.; GOMES, R. Sexualidade na adolescência: um estudo bibliográfico. Rev. Latino-Am. Enfermagem, Ribeirão Preto, v. 8, n. 2, p. 18-24, abr. 2000. Disponível em: http://dx.doi.org/10.1590/S010411692000000200004. Acesso em: 20 jul. 2018.

CARVALHO, A. M. P. Ciências no Ensino Fundamental. Cadernos de Pesquisa, São Paulo, n. 101, p. 152-168, jul. 1997. Disponível em:

http://publicacoes.fcc.org.br/ojs/index.php/cp/article/view/757. Acesso em: 15 abr. 2020.

DESSEN, M. A.; POLONIA, A. C. A família e a escola como contextos de desenvolvimento humano. Paidéia, Ribeirão Preto, v. 17, n. 36, p. 21-32, abri., 2007. Disponível em: https://doi.org/10.1590/\$0103-863X2007000100003. Acesso em: 20 out. 2018.

FALEIROS, F.; KÄPLER, C.; SILVA, S. S. C.; GOES, F. S. N.; CUCIK, C. D. Uso de questionário online e divulgação virtual como estratégia de coleta de dados em estudos científicos. Texto \& Contexto Enfermagem, Florianópolis, v. 25, n. 4, out. 2016. Disponível em: https://doi.org/10.1590/0104-07072016003880014. Acesso em: 15 ago. 2018.

FILHO, R. B. S.; ARAÚJO, R. M. L. Evasão e abandono escolar na educação básica no Brasil: fatores, causas e possíveis consequências. Educação Por Escrito, Porto Alegre, v. 8, n. 1, p. 35-48, jan.-jun. 2017. Disponível em: http://dx.doi.org/10.15448/2179-8435.2017.1.24527. Acesso em: 20 abr. 2020.

GADÉA, S. J. S.; DORN, R. C. Alfabetização científica: pensando na aprendizagem de ciências nas séries iniciais através de atividades experimentais. Experiências em Ensino de Ciências, Cuibá, v. 6, n.1, p. 113-131, 2011. Disponível em: http://if.ufmt.br/eenci/?go=artigos\&idEdicao=27. Acesso em: 04 abr. 2018.

GEHLEN, S. T.; MALDANER, O. A.; DELIZOICOV, D. Momentos pedagógicos e as etapas da situação de estudo: complementaridades e contribuições para o ensino de ciências. Ciência \& Educação, Bauru, v. 18, n. 1, p. 1-22, 2018. Disponível em: https://doi.org/10.1590/S1516-73132012000100001. Acesso em: 28 abr. 2020.

GUIMARÃES, C. R. A.; SILVA, F. C. V.; NETO, J. E. S.. Modos de pensar sobre entropia e espontaneidade de licenciandos em química a partir da teoria dos perfis conceituais. АCTIO, Curitiba, v. 4, n. 2, p. 15-29, mai./ago. 2019. Disponível em: https://periodicos.utfpr.edu.br/actio/article/view/8836. Acesso em: 15 abr. 2020.

JOENK, I. K. (2002) Uma introdução ao estudo de Vygotsky. Linhas, Florianópolis, UDESC, v. 3, n. 1, p. 1-12, 2002. Disponível em:

http://www.periodicos.udesc.br/linhas/ojs/include/getdoc. php?id=95\&article=87 \&mode=pdf. Acesso em: 15 mar. 2020.

MOREIRA, D. Z.; RODRIGUES, M. B. Saúde mental e trabalho docente. Estudos de Psicologia, Natal, v. 23, n. 3, p. 236-247, set., 2018. Disponível em: 
OLIVEIRA, G. W. B.; JACINSKI, L. Desenvolvimento de questionário para coleta e análise de dados de uma pesquisa, em substituição ao modelo Google Forms. 2017. 51 f. Trabalho de Conclusão de Curso. Universidade Tecnológica Federal do Paraná, Ponta Grossa, 2017. Disponível em:

http://repositorio.roca.utfpr.edu.br/jspui/bitstream/1/8339/1/PG_COADS_2017_ 2_06.pdf. Acesso em: 12 ago. 2018.

PIASSI, L. P. Educação científica no ensino fundamental: os limites dos conceitos de cidadania e inclusão veiculados nos PCN. Ciência \& Educação, Bauru, v. 17, n. 4, p. 789-805, 2011. Disponível em: https://doi.org/10.1590/S151673132011000400002. Acesso em: 06 set. 2018.

PIRES, M. G.; DALARIVA, K. C.; FERNANDES, C.; FRAGA, C. S.; SALDANHA, T.; SOUZA, M. C.; FAILACE, D. M.; ROSITO, B. A. (2007). Motivações e expectativas de alunos/as do ensino fundamental na participação de um clube de ciências. In: Anais do VI Encontro Nacional de Pesquisa em Educação em Ciências. Florianópolis, SC. Disponível em: http://www.nutes.ufrj.br/abrapec/vienpec/CR2/p363.pdf. Acesso em: 03 jun. 2018.

PRADO, L.; WESENDONK, F. S. Objetivos de utilização da experimentação presentes em produções acadêmico-científicas publicadas nos anais de um evento da área de ensino de ciências. ACTIO, Curitiba, v. 4, n. 2, p. 148-168, mai./ago. 2019. Disponível em:

https://periodicos.utfpr.edu.br/actio/article/view/9236/6469. Acesso em: 06 mai. 2020

ROSA, C. W.; ROSA, A. B.; PECATTI, C. Atividades experimentais nas séries iniciais: relato de uma investigação. Revista Electrónica de Enseñanza de las Ciencias, v. 6, n. 2, p. 263-274, 2007. Disponível em:

http://reec.uvigo.es/volumenes/volumen6/ART3_Vol6_N2.pdf. Acesso em: 03 ago. 2018.

SILVA, E. T.; SÁ, R. A.; BATINGA, V. T. S. A resolução de problemas no ensino de ciências baseada em uma abordagem investigativa. ACTIO, Curitiba, v. 4, n. 2, p. 169-188, mai./ago. 2019. Disponível em:

https://periodicos.utfpr.edu.br/actio/article/view/9535/6499. Acesso em: mai. 2020.

VYGOTSKY, L. S. A formação social da mente: o desenvolvimento dos processos psicológicos superiores. São Paulo: Martins Fontes, 1984.

VYGOTSKY, L. S. Pensamento e linguagem. São Paulo: Martins Fontes, 1989. 
Recebido: 19 mai. 2020

Aprovado: 20 jul. 2020

DOI: $10.3895 /$ actio.v5n3.12408

Como citar:

MARTINS, I. F.; ARANTES, S. L. F Concepções de professores de ciências biológicas sobre as aulas práticas. ACTIO, Curitiba, v. 5, n. 3, p. 1-20, set./dez. 2020. Disponível em:

$<$ https://periodicos.utfpr.edu.br/actio>. Acesso em: XXX

Correspondência:

Shirley de Lima Ferreira Arantes

Av. São Paulo, n 3.996, Vila Rosário, Ibirité, Minas Gerais, Brasil.

Direito autoral: Este artigo está licenciado sob os termos da Licença Creative Commons-Atribuição 4.0

Internacional.

(c) (1) 